\title{
Improving the Gibraltar/Reykjavik NAO Index
}

\author{
B. M. Vinther, K. K. Andersen and A. W. Hansen \\ Niels Bohr Institute for Astronomy, Physics and Geophysics, University of Copenhagen, Copenhagen, Denmark
}

T. Schmith

Danish Meteorological Institute, Copenhagen, Denmark

P. D. Jones

Climatic Research Unit, University of East Anglia, Norwich, UK.

The longest instrumental index of the North Atlantic Oscillation (NAO) is based on pressure measurements from Gibraltar and Reykjavik. Recently two long pressure series from the town of Cádiz and the nearby San Fernando observatory in southern Spain have been digitized. As Gibraltar is situated within 100 kilometers from Cádiz and San Fernando a long held suspicion that early pressure data from Gibraltar contains several problems can now be investigated. This leads to the creation of an improved version of the long NAO index in which the period from 1821 to 1856 has been revised.

\section{Introduction}

During the last decade interest in the North Atlantic Oscillation (NAO) has increased markedly as its influence on climate in the North Atlantic region has become more and more evident [Hurrell, 1995; 1996; Hurrell and van Loon 1997; Hurrell et al., 2003]. The importance of the NAO has also led to a strong desire to extend our knowledge of its behavior further back in time [Jones et al. 2001]. As instrumental pressure data at the centers of action of the NAO (Iceland and the Azores/Iberia) are available for the past $\sim 180$ years only [Jones et al., 1997] many efforts have been made to reconstruct the NAO from early instrumental and documentary data [Luterbacher et al. 1999; 2002] as well as various proxy data [Cook, 2003; Vinther et al., 2003].

All NAO reconstructions are characterized by some kind of verification process in which an instrumental NAO index is used for comparison with the proposed NAO reconstruction. For these verification purposes it is of immense importance to have as long and as accurate an instrumentally based index of the NAO as possible.

During the recently concluded IMPROVE project a range of high quality pressure series was generated. Of particular interest for improving the Gibraltar/Reykjavik NAO index are the new series from Cádiz and San Fernando in southern Spain [Barriendos et al., 2002]. As these two observation sites are located only a few kilometers apart it is possible to create an homogenous pressure series spanning almost two centuries. Furthermore their proximity to Gibraltar gives the opportunity to independently verify the Gibraltar data. In a recent paper [Jones et al., 2003] such an effort led to the conclusion that the combined Cádiz/San Fernando (CSF) record was inhomogeneous. Here however we postulate that the inhomogeneities in the Cádiz and San Fernando records

Copyright 2003 by the American Geophysical Union. $0094-8276 / 03 / \$ 5.00$ can be removed and a new homogenized version of the combined CSF pressure record can be created. A comparison between the new CSF and the Gibraltar pressure records is carried out leading to the development of an improved version of the Gibraltar/Reykjavik NAO index for the period 1821 to 1856 .

\section{The Cádiz and San Fernando Pressure Records}

Table 1 provides general information on the Cádiz and San Fernando observatory locations.

\subsection{Cádiz Observation Details}

19th century observations in Cádiz can broadly speaking be categorized as follows: Observations carried out by the Urrutia brothers and other observations. During more than 50 years the three Urrutia brothers took three daily observations every day, for every month in every year. No gaps in their impressive observation series except for the years 1851 and 1852 where their notebooks are missing [Barriendos et al., 2002].

A drawback concerning the observations performed by the Urrutia brothers is the complete lack of metadata. Not even the exact location of their instruments is known. Nevertheless their observations seem to be of high quality.

The other 19th century pressure series from Cádiz are short and discontinuous. Hence the recently digitized 1821 to 1869 period of the thrice daily observations carried out by the Urrutia brothers [Barriendos et al., 2002] will be used for creating the combined CSF record.

\subsection{San Fernando Observation Details}

At the San Fernando Naval Observatory situated nearby Cádiz systematic hourly pressure observations have been performed for more than a century. Daily mean pressure has been digitized for the period 1870 to 2000 . The data are generally of excellent quality except for the two last decades where some inhomogeneities remain [Barriendos et al., 2002; Jones et al., 2003].

From the period 1850 to 1885 an old tabulation of monthly mean pressure from the San Fernando observatory can be found in Hann [1887]. For the 1870-1885 period the tabulation is practically identical to the newly digitized data as both data sets have the same source. The 1850 to 1869 part of the old tabulation has been obtained by Hann [1887] from Cecilio Pujazón the director of the San Fernando observatory in the late 19th century. Hence the old tabulation can be expected to be highly reliable.

\section{Homogenizing the Pressure Data}

\subsection{Cádiz Observations}

As no metadata are available for the Cádiz pressure observations the only way of assessing the homogeneity of the 
Table 1. Early Pressure Series from Stations Located in the Southern Part of the Iberian Peninsula.

\begin{tabular}{lcrrl}
\hline Station & Start Year (A.D.) & Latitude $\left({ }^{\circ} \mathrm{N}\right)$ & Longitude $\left({ }^{\circ} \mathrm{W}\right)$ & Source \\
\hline Cádiz & $1816^{a}$ & 36.5 & 6.2 & Barriendos et al., 2002 \\
Gibraltar & 1821 & 36.2 & 5.4 & Jones et al. 1997. \\
San Fernando & 1850 & 36.5 & 6.3 & Barriendos et al., 2002 $^{b}$ \\
\hline
\end{tabular}

${ }^{a}$ Discontinuous observations since 1786 A.D.

${ }^{b}$ The source for the $1850-1869$ period is: Hann, 1887.

series is by studying the data themselves. A comparison between the Cádiz and the San Fernando mean monthly pressure data yields two results. First, corrections to the San Fernando data applied by Hann [1887] are not consistent with the Cádiz series (the corrections were based partly on suspect Lisbon pressure data). Removing the corrections from the San Fernando series improves monthly correlations between the two pressure series markedly (see table 2). Second, having removed the Hann corrections from the San Fernando data a yearly cycle in the mean monthly pressure differences between Cádiz and San Fernando is revealed (see figure 1). Cádiz data shows systematic deviations from the San Fernando values with higher values measured in Cádiz during summer months and lower values during winter months as compared to San Fernando.

It is well known that a wide range of factors can contribute to inhomogeneities in pressure series [Schmith et al., 1997]. Nevertheless an inhomogeneity which varies with an annual cycle with an amplitude of $\sim 1 \mathrm{hPa}$ strongly suggests a lack of correction for barometer temperature in the Cádiz data. As no metadata are available for the Cádiz pressure series the only means of correcting the pressure data is to use the outdoor temperature measurements also performed thrice daily by the Urrutia brothers [Barriendos et al., 2002]. Hence corrections were applied to each of the thrice daily pressure observations using the standard formula:

$$
C=-B \alpha t
$$

Here $\mathrm{C}$ is the correction, $\mathrm{B}$ is uncorrected pressure, $\alpha$ is the volume thermal expansion coefficient for the combined mercury-scale system $\left(\alpha=1.818 \cdot 10^{-4} /{ }^{\circ} C\right)$ and the barometer temperature in Celsius [Schmith et al., 1997].

The mean monthly differences between the temperature corrected Cádiz data and the San Fernando data are shown in figure 1 . It can be seen that the annual cycle in the difference is now completely removed. This strongly supports the validity of the correction. It should however be noted that a constant difference between the two pressure series remains. The complete lack of Cádiz metadata however impedes further clarification on the possible causes of this difference. It is likely to be the result of a barometer index error.

Finally an inhomogeneity of unknown origin between the years 1835 and 1836 was found. This inhomogeneity results in a mean pressure which is lower during 1821-35 as compared to $1836-69$.

\subsection{San Fernando Observations}

As mentioned in the previous section corrections applied by Hann [1887] to the early tabulation of San Fer-

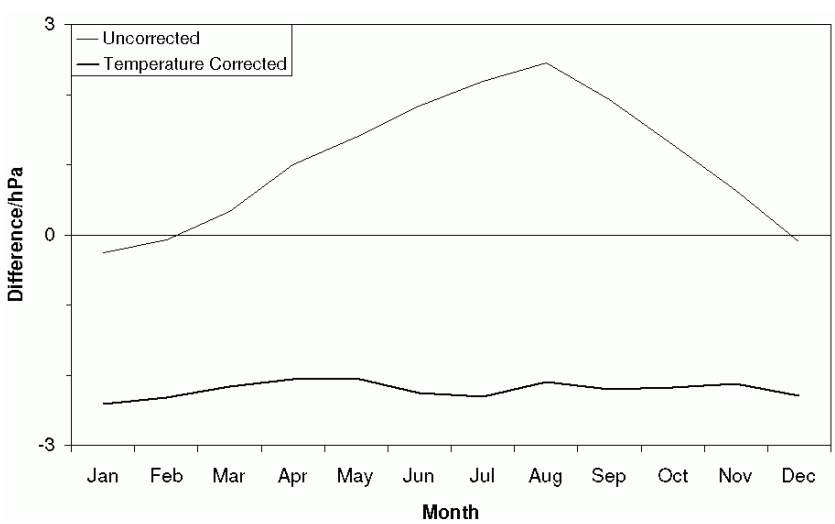

Figure 1. Cádiz minus San Fernando Mean Monthly Pressure (1853-1869). Before and After Cádiz Pressure Observations were Corrected for Temperature

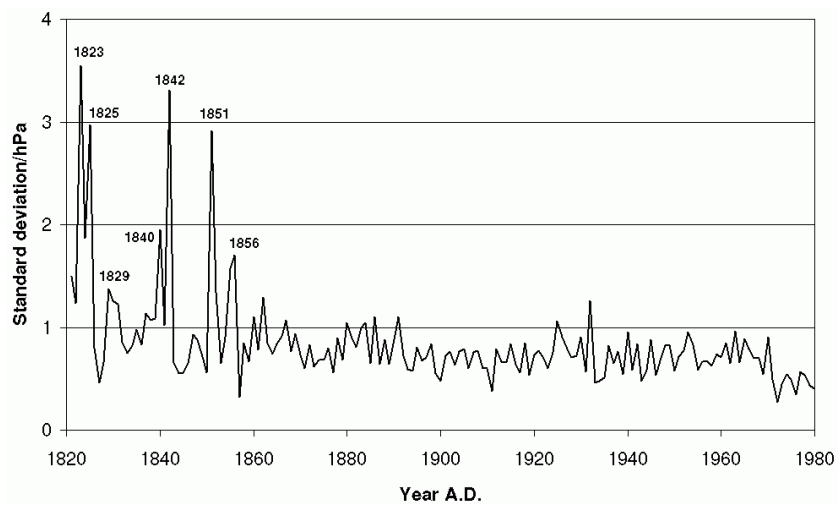

Figure 2. Standard Deviations of Monthly Pressure Differences Between the Gibraltar and CSF Observation Series.

nando data were removed. These corrections amounted to $0.3 \mathrm{mmHg}(1850-54), 1.2 \mathrm{mmHg}(1855)$ and $0.7 \mathrm{mmHg}$ (1856$67)$. As the tabulation gave pressures in $\mathrm{mmHg}$ the corrections were subtracted before conversion to hPa (conversion factor $1.333 \mathrm{hPa} / \mathrm{mmHg}$ ).

The newly digitized part of the San Fernando series (18702000) contains suspected inhomogeneities in the last two

Table 2. Monthly Correlations Between Cádiz and San Fernando Pressure Observations Before and After Corrections were Removed from the San Fernando Pressure Series. Correlations are Calculated for the Period 1853-1869.

\begin{tabular}{lccccccccrrrr}
\hline & Jan & Feb & Mar & Apr & May & Jun & Jul & Aug & Sep & Oct & Nov & Dec \\
\hline Before & 0.98 & 0.99 & 0.98 & 0.85 & 0.80 & 0.43 & 0.80 & 0.82 & 0.55 & 0.95 & 0.96 & 0.99 \\
After & 0.99 & 0.99 & 0.99 & 0.93 & 0.85 & 0.57 & 0.93 & 0.92 & 0.81 & 0.98 & 0.99 & 1.00 \\
\hline
\end{tabular}


Table 3. Corrections Applied to the Mean Monthly Values of the Cádiz and San Fernando Pressure Series.

\begin{tabular}{lcc}
\hline Period & Observation Station & Correction $/ \mathrm{hPa}$ \\
\hline $1821-35$ & Cádiz (Urrutia Brothers) & 5.4 \\
$1836-50$ & Cádiz (Urrutia Brothers) & 3.1 \\
$1851-69$ & San Fernando (Naval Obs.) & 0.9 \\
\hline
\end{tabular}

Table 4. Correlations with Reykjavik Seasonal Pressure

\begin{tabular}{lccccc}
\hline Pressure Series & Period & DJF & MAM & JJA & SON \\
\hline Cádiz/San Fernando & $1825-1856$ & -0.55 & -0.20 & -0.08 & -0.37 \\
Gibraltar & $1825-1856$ & -0.50 & -0.18 & -0.02 & -0.17 \\
Gibraltar & $1857-1999$ & -0.68 & -0.34 & +0.16 & -0.29 \\
San Fernando & $1857-1980^{a}$ & -0.72 & -0.31 & +0.05 & -0.31 \\
\hline
\end{tabular}

${ }^{a}$ Except the year 1950.

decades as well as the year 1950 which shows abnormally low pressures throughout the year. A further discussion of these inhomogeneities is beyond the scope of this paper.

\subsection{The Combined Series}

To create a single homogenous pressure record from the Cádiz and San Fernando series it is assumed that each homogenous period of observation has the same mean pressure. This assumption has been applied successfully to a large inhomogeneous European pressure database before [Slonosky et al., 1999]. Further, the San Fernando data are chosen when both Cádiz and San Fernando data are available. The choice being a consequence of the better documentation of the San Fernando series. Finally it is required that overlapping homogeneous periods of observations have the same mean pressure in the overlapping years.

Using these assumptions corrections were calculated for the 1821 to 1869 period. The reference period was chosen to be the longest homogenous period (1870-1980, not using the single year of 1950). The corrections are given in table 3 It should be noted that Cádiz observations were chosen over the San Fernando observations for the year 1850 as at least the month of January 1850 disagreed markedly with both

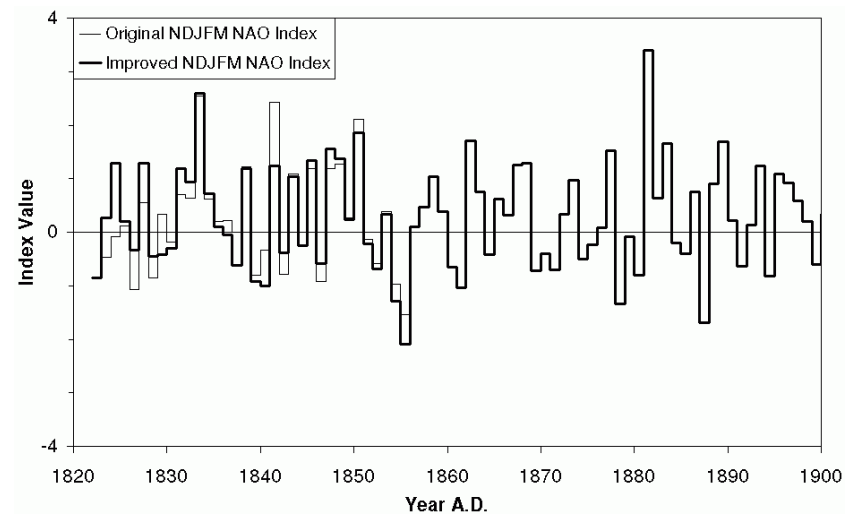

Figure 3. November to March Values of the Orignal and the Improved NAO Index.
Cádiz and the nearby Gibraltar (see table 1) pressure records [Jones et al., 1997].

\section{Comparison Between the Gibraltar and the New CSF Pressure Series}

To asses the quality of both the Gibraltar and the new CSF pressure record, monthly pressure differences between the two series were calculated for all months during the period 1821 to 1980 . Subsequently the standard deviations for the monthly differences were calculated for each year in the period (see figure 2).

From figure 2 it can be seen that the standard deviation of the monthly pressure differences (for a single year) are generally around or below $1 \mathrm{hPa}$ in the years after 1856 . In 1856 and before however, large excursions in the pressure differences are observed. The deviation peaks in 1829, 1840, 1842 and 1851 coincide exactly with shifts in corrections applied in order to homogenize the Gibraltar pressure record [Jones et al., 1997]. The early peaks in 1823 and 1825 are probably also explained by inhomogeneities in the Gibraltar series as some months are missing in the early part of that record. The only deviation peak not obviously explained by inhomogeneities in the Gibraltar record is the one corresponding to the years 1855 and 1856. In these years however observations are available from both Cádiz and San Fernando. An analysis similar to the one presented in figure 2 yields standard pressure deviations between Cádiz and San Fernando of only $0.5 \mathrm{hPa}$ and $0.2 \mathrm{hPa}$ for the two years. Hence the Gibraltar record is most probably to blame for the large deviation peaks in figure 2 .

Finally the agrement between the Gibraltar and the CSF record in the period from 1832 to 1839 suggests that the timing of the shift in corrections (1835/36) applied to the Cádiz record is very reasonable.

\section{Improving the NAO Index}

The Gibraltar/Reykjavik NAO index is created by normalizing each of the pressure series with respect to the 195180 period and subsequently subtracting the Reykjavik normalized pressure from Gibraltar normalized pressure.

As pre-1857 pressure data from CSF has been shown to be more reliable than the data from Gibraltar, the CSF series is now an obvious choice for a southern station in a NAO index. There is however the problem that modern San Fernando data has considerable problems such as changes of stations and instruments [Barriendos et al., 2002]. Therefore the most desirable solution is to change the southern station from Gibraltar to CSF for the 1821-56 period only. This decision relies on the fact that pressure variations are very similar in CSF and Gibraltar. Thus shifting the southern station should not by itself create inhomogeneities in the NAO index.

That the CSF series is indeed more suitable for calculating the NAO in the first half of the 19th century than the Gibraltar series is also suggested by table 4. CSF pressure correlates slightly higher with Reykjavik than does Gibraltar pressure for their common complete 1825-56 period. The early CSF series thus more in line with later observed correlations between Reykjavik and Gibraltar as well as Reykjavik and CSF (see table 4).

Table 5. Monthly Pressure Standard Deviations for the Period 1951-80. All values are given in hPa.

\begin{tabular}{lrrrrrrrrrrrr}
\hline Station & Jan & Feb & Mar & Apr & May & Jun & Jul & Aug & Sep & Oct & Nov & Dec \\
\hline Before Gibraltar & 3.2 & 3.5 & 3.4 & 1.9 & 1.4 & 1.0 & 0.8 & 0.9 & 1.1 & 2.1 & 2.3 & 3.0 \\
San Fernando & 3.3 & 3.4 & 3.1 & 1.9 & 1.3 & 0.9 & 0.7 & 0.7 & 0.9 & 2.0 & 2.5 & 3.2 \\
\hline
\end{tabular}


Hence a new version of the NAO index using CSF and Reykjavik pressure data for the 1821-56 period was calculated. The reference period again being 1951-80 for the normalization. Standard deviations for each month in the reference period are given for both Gibraltar and CSF in table 5. Note that the similarities of the values confirms the validity of using Gibraltar and CSF pressure variations (almost interchangeably). Nov-Mar values of the new improved NAO index and the original Gibraltar/Reykjavik NAO index are presented in figure 3.

\section{Comparison with NAO Proxies}

No alternative NAO index based on pressure observations in the centers of action of the NAO is presently available for the pre-1857 period. Hence further verification of the improved NAO has to be based on comparisons with NAO proxies. This is however problematic because most reconstructions of the NAO are either partly based on the Gibraltar pressure series [Luterbacher et al., 2002], calibrated against the original Gibraltar/Reykjavik NAO index [Cook, 2003] or proven to be unreliable [Cook, 2003].

Only the NAO proxy presented by Vinther et al. [2003] is both independent of the Gibraltar data and of sufficient quality for a meaningful comparison to take place. From multiple Greenland ice core records Vinther et al. [2003] derived a southern Greenland winter temperature index. As the NAO strongly influences winter temperatures in southern Greenland the temperature index can also be used as a NAO proxy. It should however be noted that the NAO and the Greenland winter temperatures are negatively correlated.

The longest period for which NAO winter (Dec-Mar) data are continuously available for both the original and the improved NAO index is 1824-56. Correlations between the southern Greenland temperature index and the two versions of the NAO index were calculated for this period. Dec-Mar values of the new improved NAO index correlate at $r=-0.52$ with the southern Greenland winter temperature index. The original NAO index correlated at $\mathrm{r}=-0.49$. Hence the improved NAO index agrees better with the NAO proxy presented by Vinther et al. [2003].

\section{Conclusion}

Recently digitized pressure observations from Cádiz and San Fernando situated in southern Spain were compared to the Gibraltar pressure record. The comparison shows good agreement between all pressure records except for some of the years between 1821 and 1856. The disagreements during that period were found to coincide with known uncertainties in the Gibraltar record.

The longest instrumental NAO index presently available is based partly on the Gibraltar pressure record. Having demonstrated the deficiencies of the early Gibraltar record the early part of the NAO index was revised. Hence an improved version of the NAO index was created in which Gibraltar data were exchanged with Cádiz and San Fernando observations for the 1821-56 period.

The improved NAO index will provide a better foundation for verifying future NAO reconstructions. A more solid basis for future investigations of NAO influence on 19th century Northern Hemisphere climate is also given by the new version of the NAO index.

Acknowledgments. We would first and foremost acknowledge the enormous task of collecting and digitizing the early European pressure data during the IMPROVE project. KKA thanks the Carlsberg foundation for funding. PDJ acknowledges support of the Office of Science (BER), U.S. Dept. of Energy, Grant No. DE-FG02-98ER62601. Finally the two anonymous reviewers are thanked for their helpful comments and suggestions.

\section{References}

Barriendos, M., J. Martín-Vide, J. C. Peña and R. Rodríguez, Daily meteorological observations in Cádiz-San Fernando. Analysis of the documentary sources and the instrumental data content (1786-1996), Climatic Change, 53, 151-170, 2002.

Cook, E. R., Multi-Proxy Reconstructions of the North Atlantic Oscillation (NAO) Index: A Critical Review and a New WellVerified Winter NAO Index Reconstruction Back to AD 1400, In North Atlantic Oscillation, Climatic Significance and Environmental Impact, Geophysical Monograph., 134, 63-79, 2003.

Hann, J. Die Vertheilung des Luftdruckes über Mittel- und SüdEuropa, Geographische Abhandlung, Band II, Heft 2, 220 pp., Vienna, 1887.

Hurrel, J. W., Decadal trends in the North Atlantic Oscillation regional temperatures and precipitation, Science, 269, 676-679, 1995.

Hurrel, J. W., Influence of variations of extratropical wintertime teleconnections on Northern Hemisphere temperatures, grl, 23, 665-668, 1996.

Hurrel, J. W. and H. van Loon, Decadal variations in climate associated with the North Atlantic Oscillation, Climatic Change, 36, 301-326, 1997.

Hurrel, J. W., Y. Kushnir, G. Ottersen and M. Visbeck, An Overview of the North Atlantic Oscillation, In North Atlantic Oscillation, Climatic Significance and Environmental Impact, Geophysical Monograph., 134, 1-35, 2003.

Jones, P. D., T. Jonsson and D. Wheeler, Extension to the North Atlantic Oscillation using early instrumental pressure observations from Gibraltar and south-west Iceland, Int. J. Climatol., 17, 1433-1450, 1997.

Jones, P. D., T. J. Osborn and K. R. Briffa, The evolution of climate over the last millinium, Science., 292, 662-667, 2001.

Jones, P. D., T. J. Osborn and K. R. Briffa, Pressure-Based Measures of the North Atlantic Oscillation (NAO): A Comparison and an Assesment of Changes in the Strength of the NAO and in its Influence on Surface Climate Parameters, Geophysical Monograph., 134, 51-62, 2003.

Luterbacher, J., C. Schmutz, D. Gyalistras, E. Xoplaki and H. Wanner, Reconstruction of Monthly NAO and EU Indices back to AD 1675, Geophys. Res. Lett., 26, 2745-2748, 1999.

Luterbacher, J., et al, Extending North Atlantic Oscillation reconstructions back to 1500 , Atmospheric Science Letters, 2002.

Schmith, T., H. Alexandersson, K. Iden and H. Tuomenvirta, North Atlantic-European pressure observations 18681995 (WASA dataset version 1.0), Danish Meteorological Institute, Tecnical Report, 97-03, 1997.

Slonosky, V. C., P. D. Jones and T. D. Davis, Homogenization techniques for European mean monthly pressure series, J. Climate, 27, 2658-2672, 1999.

Vinther, B. M., S. J. Johnsen, K. K. Andersen, H. B. Clausen and A. W. Hansen, NAO signal recorded in the stable isotopes of Greenland ice cores, Geophys. Res. Lett., 30(7), 1387, doi:10.1029/2002GL016193, 2003.

B. M. Vinther, K. K. Andersen and A. W. Hansen, Niels Bohr Institute for Astronomy, Physics and Geophysics, Juliane Maries Vej 30, DK-2100 Copenhagen Oe., Denmark. (bo@gfy.ku.dk)

T. Schmith, Danish Meteorological Institute, Lyngbyvej 100, DK-2100 Copenhagen Oe., Denmark.

P. D. Jones, Climatic Research Unit, University of East Anglia, Norwich NR4 7TJ., UK. 